\title{
Çok Bölmeli Araç Rotalama Problemi için Bir Melez Genetik Algoritma
}

\section{A Hybrid Genetic Algorithm for Multi-Compartment Vehicle Routing Problem \\ Kazım Erdoğdu $1^{*}$}

${ }^{1}$ Yașar Üniversitesi, Mühendislik Fakültesi, Yazılım Mühendisliği Bölümü, İzmir, TÜRKIYE Sorumlu Yazar / Corresponding Author*: kazim.erdogdu@yasar.edu.tr

\section{$\ddot{\mathbf{O z}}$}

$\mathrm{Bu}$ çalışmada, Çok Bölmeli Araç Rotalama Problemi (ÇB-ARP) ele alınmıştır. Günlük hayatta marketler, firmalar ve kurumlar bazı ürünleri müșterilerine teslim ederken ya da belirli noktalardan toplarken, bu ürünleri araç içinde farklı bölmelere koymaları gerekmektedir. Bazı ürünlerin oda sıcaklığında, bazılarının soğuk olarak taşınması gerekmektedir. Bazı atıkların, kimyasal ürünlerin ya da yakıtların diğer ürünlerle karıstırılmadan tașınması gerekmektedir. Bu yüzden dağıtım ya da toplama yapan araç filosundaki her bir aracın birden fazla bölmeye sahip olması ve dağıtılan ya da toplanan ürünlerin ilgili bölmelerde taşınması gerekmektedir. Bu makalede çalışılan ÇB-ARP, bir, iki ve üç bölmeli araç senaryoları dahilinde ayrı ayrı ele alınmıștır. Çözüm yöntemi olarak melez bir Genetik Algoritma (GA) kullanılmış ve bu algoritma Araç Rotalama Problemi (ARP) literatüründe sıklıkla kullanılan bir problem örnek seti üzerinde uygulanmıștır. Sonuç olarak bu çalıșmadaki ÇBARP modeli için yeni referans sonuçları üretilmiș ve sonuçlar yorumlanmıștır.

Anahtar Kelimeler: Çok Bölmeli Araç Rotalama Problemi, Melez Genetik Algoritma, Sezgisel Arama

\begin{abstract}
In this study, a Multi-Compartment Vehicle Routing Problem (MC-VRP) was studied. In daily life, markets, companies and organizations need to load their certain products into different compartments in vehicles during the delivery or collecting of these products. Some of the products need to be carried in cold temperature while others in ambient temperature. Some wastes, chemical products or fuel types need to be transported in the same vehicle separately. Therefore, the transportation fleet must have vehicles with separate compartments and the different products must be either delivered or collected in related compartments of these vehicles. The MC-VRP studied in this paper was taken into consideration with three scenarios of vehicles with one-, two-, or threecompartments. As the solution method, a hybrid Genetic Algorithm (GA) was used and applied on a well-known problem instance set in Vehicle Routing Problem (VRP) literature. As a result, new benchmark results were obtained for the version of MC-VRP in this study and these results were evaluated.
\end{abstract}

Keywords: Multi-Compartment Vehicle Routing Problem, Hybrid Genetic Algorithm, Heuristic Search 
DEÜ FMD 23(67), 71-80, 2021

\section{Giriş}

Araç Rotalama Problemi (ARP)'nin bir türü olan Çok Bölmeli Araç Rotalama Problemi (ÇB-ARP), lojistik, nakliye, dağıtım, toplama ve tedarik zinciri alanlarında sıkça karşılaşılan bir problemdir. ÇB-ARP'de, aynı klasik ARP'de olduğu gibi, belirli sayıda müşterinin talepleri mevcut araç filosu aracılığıyla tedarik edilmeye çalışılır. Klasik ARP'ye göre fark, araçların farklı türde talepleri birbirinden ayrı şekilde taşıyabildikleri bölmelere sahip olmasıdır Araçlar depodayken, müşterilerin farklı türdeki talepleri, araçların ilgili bölmelerine yüklenir. Yüklü araçlar depodan yola çıkarak sırasıyla müșterilerine taleplerini dağıtır ve dağıtma işini bitirdiklerinde depoya geri dönerler. ÇB-ARP'de amaç, tüm araçların neden olduğu toplam maliyeti en aza indirgemektir. Bu maliyet, klasik ARP'deki gibi toplam dolașllan mesafe olabildiği gibi, harcanan zaman, tüketilen yakıt miktarı, finansal maliyetler (ücretler, vergiler, masraflar, vb.) veya çevre kirliliğine neden olan gazlar da olabilmektedir. Problemin amaç fonksiyonu, üzerinde çalıșılan problemin amacına göre belirlenmektedir.

ÇB-ARP'nin oldukça geniş uygulama alanı vardır. Örneğin bazı market zincirleri, ana depodan bayilerine veya müşterilerine ürünlerini taşırken, farklı sıcaklıklarda (özellikle soğuk ve dondurulmuş olarak) taşınması gereken ürünleri aracın ayrı bölmelerine koyarak taşımaları gerekmektedir. Ya da, benzin, mazot, vb. farklı türden yakıtların merkezden diğer yakıt istasyonlarına nakliyesinde kullanılan araçlar her bir yakıt türü için ayrı bölme içermektedir. Diğer bir örnek olarak ise tıbbi atıkların ya da geri dönüşüm atıklarının ayrı bölmelere sahip araçlarla toplanması gösterilebilir. Bunlara benzer birçok alanda ÇBARP önemli rol oynamakla birlikte yaygın uygulama alanına sahiptir.

\subsection{Literatür taramas}

ÇB-ARP'ın ilk çalıșmaları Christofides ve ark. [1] tarafından 1979 yılında ortaya atılmış olmasına rağmen, problemin bu alanda çalıșan araștırmacıların dikkatini çekmesi daha geç dönemde olmuștur. 2008 yılında Fallahi ve ark. [2] problemin matematiksel modelini ortaya koymuş ve probleme iki bölümlü araçlar için çözüm önerilerinde bulunmuștur. Calıșılan problemde müşterilerin sadece iki tür ürün talebinde bulundukları varsayılmış ve araçların her bir bölmesi ilgili ürün tipi için ayrılmıștır. Falahi ve ark. problemlerinde iki senaryo ele almışlardır. İlkinde araçların iki bölmesi de eşit kapasitedeyken, ikinci senaryoda bu kapasiteler rastgele belirlenmiştir. Problemde, araçların aynı müşteriye farklı türdeki taleplerini farklı zamanlarda iletmesine izin verilmiștir. Ancak, müșteriye teslim edilen ürün türünün tamamının tek seferde yapılması koşulu eklenmiştir. Çözüm yöntemi olarak da iki adet sezgisel yöntem kullanılmıștır: melez bir memetik algoritma ve tabu arama algoritması. $\mathrm{Bu}$ yöntemler ARP'de iyi bilinen Christofides problem örnekleri [3] üzerinde uygulanmıștır.

Mendoza ve ark. [4] ÇB-ARP çalışmalarına müşterilerin stokastik ürün talep miktarlarını da dahil etmişlerdir. Bu tür ÇB-ARP'de her araç her bölmesi tam dolu olacak șekilde tura bașlamaktadır. Ziyeret ettiği müșterinin hangi üründen ne kadar talep ettiği ise tur sırasında rastgele belirlenmektedir. Stokastik taleplerinden dolayı bu problem Stokastik Talepli ÇB-ARP (ST-ÇB-ARP) olarak adlandırılmıștır. Mendoza ve ark. önerdikleri melez bir memetik algoritmayı, kendi ürettikleri problem örnekleri ve kendi problemlerine göre uyarladıkları Christofies problem örnekleri üzerinde iki ayrı senaryo ile uygulamıştır. İlk senaryoda, her müșterinin bütün ürünleri tek bir araç tarafindan tek seferde teslim edilirken, ikinci senaryoda müşteriler her bir ürün için ayrı seferlerde ziyaret edilebilmektedir. Ancak bu senaryoda her bir müșterinin talep etiği ürün türü tek bir seferde teslim edilmektedir.

Reed ve ark. [5] cam ve kağıt dönüşüm atıklarının toplandığ bir CB-ARP üzerinde çalışmıştır. Araçlarda kağıt ve cam için eşit kapasiteli iki ayrı bölme bulunmaktadır ve her bir müşteri tek bir araç tarafından tek seferde ziyaret edilmektedir. Çözüm yöntemi olarak da Karınca Kolonisi Optimizasyonu (KKO) kullanılmıştır. Reed ve ark. da Christofies problem örnekleri üzerinde deneysel çalışmalarını yapmışlardır.

Goodson [6] da aynı Mendoza ve ark. [4] gibi STÇB-ARP üzerinde çalışmıștır. Çalışılan problemde farklı ürün sayısı üç olarak belirlenmiş ve araçların bölmeleri eșit olacak şekilde bir tam sayıyla sabitlenmiştir. Her bir müșterinin sadece bir araç tarafından tek seferde ziyaret edilmesine izin verilmiştir. Çözüm yöntemi olarak da önermiş olduğu melez Benzetimli Tavlama (BT) kullanmıștır. 
DEÜ FMD 23(67), 71-80, 2021

Abdulkader ve ark. [7] çalıștıkları CB-ARP'yi Christofides problem örneklerini baz alarak ürettikleri kendi problem örnekleri üzerinde, bir melez KKO algoritması kullanarak çözmüşlerdir. Önceki çalışmaların çoğunda olduğu gibi, onlar da her bir müşterinin sadece bir araç tarafından tek seferde ziyaret edilmesine izin vermişlerdir. Araçların bölmeleri ise iki adettir ve birisi diğerinin 3 katı büyüklüktedir.

Henke ve ark. [8] dört farklı renkte cam atıklarının toplandığı bir ÇB-ARP üzerinde çalışmışlardır. $\mathrm{Bu}$ problemin farklı yanı, araçların bölmelerinin sabit değil esnek olușudur. Yani, araçların bölmeleri hareketli bir duvar ile birbirinden ayrılmıştır ve aracın taşıdığı cam çeşidi ve miktarına göre bu bölmeler büyüyüp küçülebilmektedir. $\mathrm{Bu}$ yüzden de çalıștıkları bu probleme Esnek ÇB-ARP (E-ÇBARP) adını vermișlerdir. Geliștirdikleri bir Değișken Komşu Arama (DKA) yöntemini, özel bir şirketten aldıkları verilerle oluşturdukları problem örnekleri üzerinde uygulamışlardır.

Hübner ve ark. [9] market zincirlerinin depolarından şubelerine farklı sıcaklıkta taşınması gereken malları ele alan bir ÇB-ARP üzerinde çalıșmıșlardır. Amaç fonksiyonu olarak toplam maliyetin (mesafe + yükleme + boşaltma maliyetlerinin) en aza indirgemesini ele almışlardır. Problemlerinde iki bölmeye sahip araçlar üzerinde durulmuştur. Bölmelerin birisi soğuk saklanması gereken gıdaları içeren dondurucu bölme ve diğeri ise oda sıcaklığına sahip bölmedir. Özel bir market zincirinden aldıkları veri ile oluşturdukları ve de rastgele olușturdukları iki problem örnek kümesi üzerinde, Büyük Komşuluk Arama (BKA) algoritması kullanarak problemlerinin deneysel sonuçlarını elde etmișlerdir.

Chen ve ark. [10] çalışmalarında, klasik ÇBARP'ye müşterilerin zaman penceresi kısıtlarını da ekleyerek ZK-ÇB-ARP'yi (Zaman Kısıtlı ÇBARP) ele almişlardır. Problemlerinde kullandıkları amaç fonksiyonları araçların toplam tur uzunlukları, yakıt tüketim masrafları ve sabit masrafların hepsini içermektedir. Araçlar eș kapasiteli iki bölmeye sahiptir. Her bir müşteri tek bir araç tarafından bir kez ziyaret edilmektedir. Chen ve ark. gerçek hayat veri setinden oluşturdukları problem örnekleri üzerinde, CPLEX yöntemini ve melezledikleri Uyarlanabilir Büyük Komşuluk Arama (UBKA) algoritmasını uygulayarak bu algoritmaların performanslarını karşılaştırmışlardır.
Chen ve ark. [11] da bir ZK-ÇB-ARP üzerinde çalıșmışlardır. Problemlerinde üç farklı tür ürün için esnek bölünmüş üç bölmeli araçlar yer almaktadır. Her bir müşterinin tek bir araç tarafından tek bir seferde ziyaret edilmesi gerekmektedir. Chen ve ark. Parçacık Sürü Optimizasyonu (PSO) algoritmasını Benzetimli Tavlama (BT) algoritması ile melezlemişler ve önerdikleri bu çözüm yöntemini Solomon problem örnekleri [12] üzerinde uygulamışlardır.

Kaabachi ve ark. [13] ÇB-ARP problemini çalışmışlardır. İki bölmeli araçların bulunduğu problemde, çözüm olarak önerdikleri iki yöntemi kıyaslamışlardır: melez Yapay Arı Kolonisi (YAK) algoritması ve melez Özuyarlamalı Genel Değişken Komşu Arama (ÖGDKA) algoritması. Problem örnekleri olarak da Abdulkader ve ark. [7]'nın çalıșmasında ortaya konulan ve yazarların kendilerinin ürettiği problem örnekleri kullanılmıștır.

Wang ve ark. [14] farklı türdeki fosil yakıtların ana depodan benzin istasyonlarına taşındığı bir ÇB-ARP çalışmışlardır. Çindeki bir yakıt nakliyesi şirketinden aldıkları veriler üzerinde UBKA algoritması kullanarak çözüm üretmiș ve elde ettikleri sonuçları, oluşturdukları KTDP (Karışık Tamsayılı Doğrusal Programlama) sonuçlarıyla karşılaştırmışlardır. Küçük boyutlu problem setlerinde KTDP'den daha hizlı bir şekilde optimum sonuçları bulmuşlardır.

Eshtehadi ve ark. [15] çalıștıkları CB-ARP'de genel olarak șehir için lojistik problemini göz önünde bulundurmuştur. Genişlettikleri UBKA algoritmasını, Londra haritası üzerinde yazarların farklı boyutlarda ürettikleri problem örnekleri üzerinde uygulamışlardır.

ÇB-ARP alanındaki çalışmalar gün geçtikçe artmakta ve problemin değișik türleri üretilmektedir. Bu çalıșmada, klasik ÇB-ARP ele alınmıştır. 2 ve 3 bölmeli araçlar için iki farklı senaryo kullanılmıștır. Yöntem olarak da iyi bilinen popülasyon tabanlı bir sezgisel yöntem olan Genetik Algoritma (GA), bilinen ve bu çalışmada geliştirilen yerel arama yöntemleriyle melezlenerek kullanılmıştır. Problemde müşterilerin her bir ürün için farklı araçlar tarafından ziyaret etmelerine izin verilmiş ancak her bir ürünün tek seferde teslim edilmesi koşulu eklenmiştir. 
DEÜ FMD 23(67), 71-80, 2021

\section{Materyal ve Metot}

\subsection{Matematiksel model}

Klasik ÇB-ARP matematiksel olarak yönsüz bir tam çizge olarak tanımlanmaktadır, $G=(N, A)$. Burada $N^{\prime}=\{1,2, \ldots, n\}$ müşterilerin kümesi ve 0 depo olmak üzere $N=N^{\prime} \cup\{0\}$, ve A da çizgedeki dügüumler arasındaki kenarların kümesidir. Müșterilerin talep ettiği ürün türleri $P=\{1,2, \ldots, m\}, \quad$ araçların kümesi $\quad V=$ $\{1,2, \ldots, v\}$, i ile j düğümleri arasındaki mesafe $c_{i j}$, araçların p. ürün için ayrılan kapasiteleri $Q_{p}$ ve her bir aracın en fazla seyahat edebileceği mesafe L olmak üzere, problemin amaç fonksiyonu ve kısıtları aşağıda verilmiştir [2]:

Amaç Fonksiyonu:

$$
\min \sum_{i, j \in N} \sum_{k \in V} c_{i j} x_{i j k}
$$

Kisitlar:

$\sum_{i \in N} x_{i j k} \leq 1 \quad \forall j \in N^{\prime}, \forall k \in V$

$\sum_{i \in N} x_{i j k}=\sum_{i \in N} x_{j i k} \quad \forall j \in N^{\prime}, \forall k \in V$

$\sum_{i \in N} x_{i j k} \leq|S|-1 \quad \forall k \in V$, $y_{j k p} \leq \sum_{i \in N} x_{i j k} \quad \forall j \in N^{\prime}, \forall k \in V$,
$\forall p \in P$

$\sum_{k \in V} y_{j k p}=1 \quad \forall j \in N^{\prime}, \forall p \in P$

$\sum_{j \in N^{\prime}} y_{j k p} q_{j p} \leq Q_{p} \quad \forall k \in V, \forall p \in P$

$\sum_{i, j \in N} c_{i j} x_{i j k} \leq L \quad \forall k \in V$

$$
\begin{array}{r}
x_{i j k} \in\{0,1\} \quad \forall i \in N, \forall j \in N, \\
i \neq j, \forall k \in V
\end{array}
$$

$y_{j k p} \in\{0,1\} \quad \forall j \in N^{\prime}, \forall k \in V$,

$$
\forall p \in P, q_{j p} \neq 0
$$

Burada (2) numaralı kısıt aynı tur içinde her bir müşterinin tek bir kez ziyaret edilmesini garantilemektedir. (3) numaralı kısit aracın turunu kendi müșterilerini atlamadan ardışık bir şekilde yapmasını sağlamaktadır. (4) numaralı kısıt aracın kendi içinde alt turlar yapmasını engellemektedir. (5) numaralı kısıt, eğer j numaralı müșterinin $\mathrm{p}$ numaralı talebi $\mathrm{k}$ aracı tarafından getirilmiyorsa talebin yanlışlıkla aracın bölme kapasitesini azaltmasını engellemektedir. (6) numaralı kısıt ise müşterinin her bir talep ettiği ürünün tek seferde bir araç tarafından getirilmesini garantilemektedir. (7) ve (8) numaralı kısitlar, araçların bölme kapasitelerini aşmalarını ve araçların maksimum seyahat sinırlarını aşmalarını engellemektedir. (9) numaralı kısıt müşterinin o araç turunda seçilip seçilmediğini belirten karar değişkenidir. (10) numaralı kısıt ise müşterinin talebi olan p ürünün o araçta olup olmadığını gösteren karar değişkenidir.

\subsection{Metotlar}

CB-ARP, NP-Zor sınıfından bir problem olduğu için [2], bu çalışmada yaygın çözüm metotlarından biri olan Genetik Algoritma (GA) kullanılmıştır.

\subsection{1 Çözüm temsili}

Problemde kullanılan çözüm tüm müșterilerin indislerinin oluşturduğu bir permütasyon ile temsil edilmiștir. ÇB-ARP'nin yapısı gereği bir müşterinin birden fazla talebi olduğu için, permütasyondaki her bir genin hangi müşteriye ve ürüne karşılık geldiğinin hesaplanması, Fallahi ve ark. [2] çalışmasındaki gibi (11) ve (12) numaralı formüller aracılığıyla yapılmıştır.

müșteri $\left(\pi_{i}\right)=\left\lfloor\left(\pi_{i}+m-1\right) / m\right\rfloor$

ürün $\left(\pi_{i}\right)=\left(\left(\pi_{i}-1\right) \bmod m\right)+1$

Burada $\pi$ permütasyonu, $\pi_{i}$ permütasyon içindeki $i$. geni, $m$ ise toplam ürün çeşit (ya da 
DEÜ FMD 23(67), 71-80, 2021

araçtaki bölme) sayısını temsil etmektedir. $n$ toplam müșteri sayısını göstermek üzere, $\pi$ 'nin boyutu $\rho=n$. m'dir.

Örneğin, toplam 5 müsterinin ve 2 farklı ürünün olduğu bir ÇB-ARP'de, $n=5, m=2, \rho=10$ olmaktadır. Müşterilerin ve ürünlerin indislenmesi ise șu şekildedir: birinci müşterinin birinci ürün talebi 1 , birinci müşterinin ikinci ürün talebi 2, ikinci müșterinin birinci ürün talebi 3, ikinci müșterinin ikinci ürün talebi 4, vb. Örneğin $n=5, m=2$ için şöyle bir permütasyon olsun, $\pi=$ $(2,1,8,4,10,5,7,10,3,6)$. Bu permütasyondaki üçüncü genin hangi müșterinin hangi ürün talebine karşılık geldiği sırasıyla (11) ve (12)'deki formüller aracıllğıyla bulunmaktadır.

müşteri $\left(\pi_{3}\right)=$ müşteri $(8)=\lfloor(8+2-1) /$ 2] $=4$.

ürün $\left(\pi_{3}\right)=$ ürün $(8)=((8-1) \bmod 2)+$ $1=2$.

Yani, permütasyondaki 8 değeri, 4. müşterinin 2. tür ürün talebi olduğunu belirtmektedir.

Kullanılan GA'daki kromozomlar çözüm temsilindeki permütasyonlardır. $\mathrm{Bu}$ permütasyonun araçlara ayrılması da literatürde en çok kullanılan Bellman Split algoritmasının ÇB-ARP'ye uyarlanmıș haliyle gerçekleştirilmektedir.

\subsubsection{Kullanılan sezgisel yöntemler}

Kullanılan GA, beş adet tur oluşturan sezgisel yöntem ve dört adet yerel arama sezgisel yöntem ile melezlenmiștir. Kullanılan bes adet tur oluşturan sezgisel yöntem şunlardır: Clark \& Wright Tasarruf Algoritması, En Yakın Komşu Algoritması, Rastgele Görev Algoritması, Rastgele Görev - Çiçek Algoritması, Tarama Algoritmasi.

Clark \& Wright Tasarruf Algoritması [16] en kötü senaryoyla, yani her bir müșteriye bir araç atamayla başlar. Ardından bu araçların turlarını sırasıyla birleștirmeye devam eder. Gidilen mesafede en çok tasarruf edilen araçlar, problemin kısıtları dahilinde birleștirilir. Birleștirilebilecek araç kalmayana kadar bu işlem devam eder.

En Yakın Komșu Algoritması ise çözüm için birbirlerine yakın müşterilerden oluşan araç turları oluşturmaya çalıșır. Her bir aracın turu oluşturulurken, ilk olarak depoya en yakın müșteri tura dahil edilir. Ardından geriye kalan müşteriler arasından turun en son müșterisine en yakın müșteri bulunur ve o da turun sonuna eklenir. Eğer kapasite, maksimum tur uzunluğu, vb. kısıtlar aşllıyorsa, yeni bir araç eklenir ve bir sonraki müșteri yine aynı en yakın komșuluk kriterine göre bu yeni aracın turuna dahil edilir. $\mathrm{Bu}$ işlem tüm müşteriler araç turlarına eklenene kadar devam eder.

Rastgele Görev Algoritması [17] En Yakın Komşu Algoritması ile aynı prensipte çalıșmaktadır. Tek farkı ise, eğer birden fazla en yakın müşteri varsa Rastgele Görev Algoritması bunları bir listeye dahil eder ve seçim yaparken bu listeden rastgele birisini seçer. Bu seçim işlemi tüm müşterilerin araç turlarına eklenmesiyle son bulur.

Rastgele Görev - Çiçek Algoritması [17] Rastgele Görev Algoritmasının geliştirilmiş halidir. Bu algoritmada her bir yeni müşteri seçilmeden önce, geriye kalan müşteriler turu depodan uzaklaştıranlar ve turu depoya yaklaștıranlar olarak iki gruba ayrılır. Araç turuna eklenecek bir sonraki müşteri seçilirken, eğer aracın kapasitesi yarısına kadar dolmamıșsa ilk gruptaki en yakın müșteri, değilse ikinci gruptaki en yakın müşteri seçilir. Bu çalışmada ÇB-ARP ele alındığ için, aracın tüm kapasitesi yerine seçilen müşteri ve talebinin karşllık geldiği araç bölmesinin kapasitesinin yarıya ulaşılıp ulașılmadığına bakılmıștır. Bu sayede araçların etkin bir şekilde müşterileri turlarına dahil etmesi sağlanmaktadır. Tüm bu ișlem, tüm müşteriler araçlara dahil edilene kadar devam eder.

Tarama Algoritması [18] tüm müşterilerin depoya olan kutupsal koordinatlarına göre açllarını belirleyerek başlar. Ardından açılarına göre müşterileri küçükten büyüğe doğru sıralar. $\mathrm{Bu}$ sıralama doğrultusunda ve kısitlar dahilinde kutupsal koordinat açısı en küçük olandan bașlayarak müşterileri sırasıyla araçların turlarına dahil eder. Tüm bu ișlem bütün müşteriler araçlara atanana kadar devam eder.

GA'da kullanılan yerel arama yöntemleri de şunlardır: 2-Opt, Yer Değiștirme, Araya Ekleme ve Araç Sayısını Azaltma.

2-Opt yönteminde [19] amaç turda iki müşteri arasındaki yolların belirli bir kurala göre yer değiştirilmesiyle mevcut permütasyonu iyileștirmektir. Tur içindeki müșteriler sırasıyla ikișer olarak yer değiştirilir ve bu iki müşterinin 
DEÜ FMD 23(67), 71-80, 2021

arasında kalan diğer müșterilerin sırası tersten yazılır. Eğer yeni oluşan tur daha iyi sonuç üretirse, aynı işlem baştan bu yeni tur üzerinden yapılır, değilse turun orijinal permütasyonu üzerinden devam edilir. Tüm bu süreç daha iyi bir sonuç üretilememesi durumuna kadar devam eder.

Yer Değiștirme sezgiseli ise, sırasıyla tur içindeki iki müşterinin yer değiştirdiği yerel aramadır. Turun birinci müșterisinden başlayarak her bir müşteri sırasıyla seçilir ve seçilen her bir müșteri turdaki diğer tüm müşterilerle yer değiștirilir. Her bir yer değiştirmede eğer tur daha da iyileşiyorsa, tur güncellenmektedir ve işlem kaldığı yerden bu güncellenmiş tur üzerinden yapılmaktadır. Tüm bu süreç mevcut turdaki tüm yer değiștirmeler bitince son bulmaktadır.

Araya Ekleme sezgiseli, Yer Değiştirme sezgiseline benzer şekilde uygulanmıştır. Farklılık olarak, her arama adımında iki müșterinin yer değiştirmesi değil, seçilen müșterinin mevcut turdaki her bir konuma eklenmesi gerçekleştirilmiştir.

Araç Sayısını Azaltma sezgiseli ise yazarın geliştirmiş olduğu bir yerel arama yöntemidir. Bu yöntemde, tüm araçlar toplam yüklerine göre küçükten büyüğe doğru sıralanır. Ardından, en az yüke sahip araçtan başlanarak, araç içindeki müşteriler sırasıyla problem kısıtları dahilinde diğer araçlarda olabilecek ve toplam tur uzunluğunu en aza indirgeyen konuma yerleștirilirler. Bu ișlem tüm araçlar üzerinde uygulandıktan sonra yerel arama sonlandırılır. $\mathrm{Bu}$ yerel aramada amaç, araçların sayısının azaltılarak toplam tur uzunluğunu azaltmaya çalışmaktır.

2-Opt ve Yer Değiştirme yerel arama yöntemleri hem çözümdeki permütasyon üzerinde hem de alt araç turları üzerinde ayrı ayrı uygulanmıștır. Bir yerel arama yönteminin ürettiği en iyi sonuç bir sonraki yerel arama için girdi olacak șekilde uygulanmıştır. $\mathrm{Bu}$ çalışmada kullanılan Yerel Arama yönteminin algoritması Şekil 1'de verilmektedir.

$$
\begin{aligned}
& \text { procedure YerelArama(Çözüm ç) } \\
& c ̧ \leftarrow 2 \text {-OptAnaTur(ç) } \\
& \text { ç } \leftarrow \text { YerDeğiştirmeAnaTur(ç) } \\
& c ̧ \leftarrow \text { ArayaEklemeAnaTur } \leftarrow \text { ç) } \\
& c ̧ \leftarrow \text { AraçSayısınıAzaltma(ç) } \\
& c ̧ \leftarrow 2 \text {-OptTümAraçTurları(ç) } \\
& \text { ç } \leftarrow \text { YerDeğiştirmeTümAraçTurları(ç) } \\
& \text { ç } \leftarrow \text { ArayaEklemeTümAraçTurları(ç) } \\
& \text { end procedure }
\end{aligned}
$$

Şekil 1. YerelArama yönteminin algoritması

\subsubsection{GA'nın uygulanması}

$\mathrm{Bu}$ çalışmada kullanılan melez GA yöntemi şu șekilde uygulanmıștır. Bașlangıç topluluğunun beş bireyi 2.2.2'de bahsedilen tur oluşturma sezgiselleriyle, geri kalan bireyler ise rastgele permütasyonlar oluşturularak elde edilmiştir. $\mathrm{Bu}$ başlangıç topluluğundaki tüm bireyler (kromozomlar) yerel arama prosedüründen geçirildikten sonra, melez GA önceden belirlenmiș tekrarlama sayısı kadar çalıștırılmıștır. Her bir tekrarda, topluluktaki bireyler çaprazlama, mutasyon ve yerel arama işlemlerinden geçirilmiş ve topluluğa dahil edilmiştir. Çaprazlama işleci olarak PMX [20], mutasyon ișleci olarak ise permütasyonda rastgele seçilen iki gen arasını ters çevirme kullanılmıştır. Çaprazlama için gerekli olan iki birey ikili turnuva seçimi ile belirlenmiștir. Seçilen bu bireylerden çaprazlama ile iki yeni birey daha üretilmiș ve sonrasında bu iki yeni birey sirasiyla mutasyon ve yerel arama işlemlerinden geçirilmiştir. $\mathrm{Bu}$ süreçlerden geçen bu yeni iki birey topluluğa eklenmiștir. Tüm bu işlemler topluluktaki birey sayısının yarısı kadar tekrarlanmıștır. Bir tekrar sonunda iki katına çıan topluluk, bir sonraki tekrara geçmeden önce başlangıçta belirlenen birey sayısına indirgenmiștir. $\mathrm{Bu}$ indirgenmede, elitizm kullanılmıș ve en iyi bireyler saklanırken geriye kalanlar nüfustan elenmiștir. Tüm bu tekrarlar esnasında elde edilen en iyi birey (en düşük toplam tur uzunluğunu veren birey) global bir değișkende tutulmuş ve her tekrar sırasında güncellenmiştir. Melez GA'nın çıktısı da bu global en iyi bireydir. Bu çalışmada kullanılan melez GA, Şekil 2'de verilmiștir. 
DEÜ FMD 23(67), 71-80, 2021

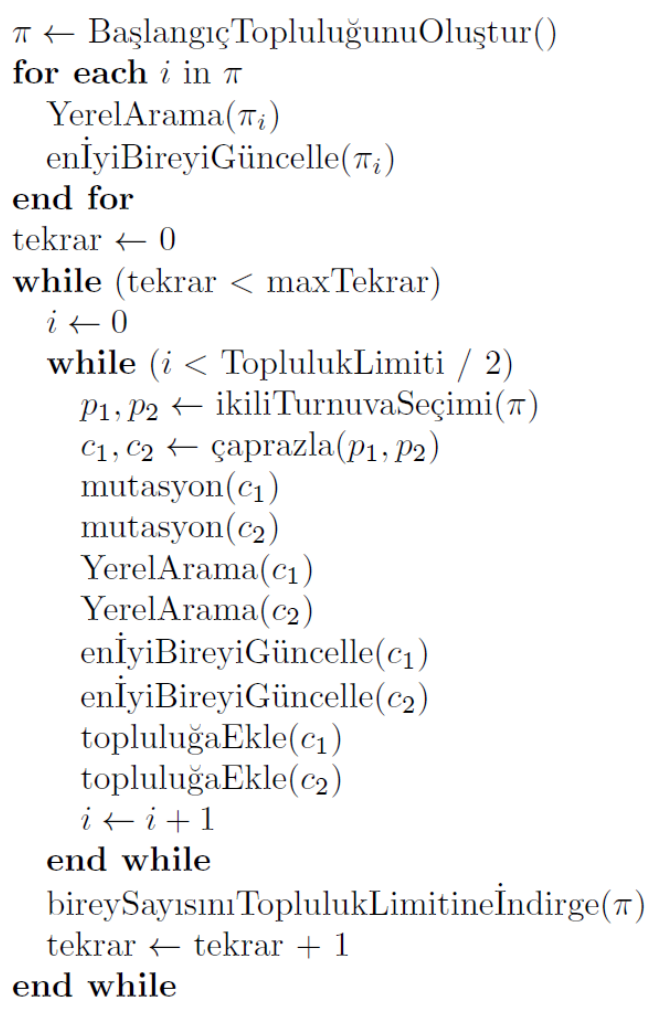

Şekil 2. Kullanılan melez GA

\section{Bulgular}

Bu çalışmada bahsedilen yöntem ve algoritmalar $\mathrm{C}++$ dilinde kodlanmıs ve Intel Core i5-7200 CPU $2.50 \mathrm{GHz}$ işlemcili ve 8GB RAM donanımlı bilgisayarda çalıştırılıp sonuçlar elde edilmiştir.

GA'da kullanılan parametreler ise şu şekildedir:

Nüfustaki Kromozom Sayısı: 100

Tekrar Sayısı: 100

Çaprazlama Yüzdesi: \%70

Mutasyon Yüzdesi: \%10

Problem örnekleri olarak, vrpncXX olarak adlandırılan ve literatürde yaygın bir şekilde kullanılan Christofides problem örnekleri seti [3] kullanılmıştır. Set içerisinde müşteri sayıları 50-199 arasında değișen toplam 14 adet problem örneği bulunmaktadır. Her bir örneğin müșteri sayısı Tablo 1'de " $n$ " bașlıklı sütunda belirtilmiștir. Örneklerde yer alan müșterilerin talepleri tekdüze dağılıma uymaktadır. Müşterilerin x ve y koordinatları, ilk 10 örnekte (vrpnc01-vrpnc10) tekdüze bir dağılıma, son 4 örnekte (vrpnc11-vrpnc14) kümelenmiș bir dağılıma sahiptir. Ayrıca, 7 problem örneğinde (vrpnc01-vrpnc05, vrpnc11-vrpnc12) tüm araçların kat edebileceği toplam tur uzunluğu sinırı (Tmax) bulunmazken, geri kalanlarda (vrpnc06-vrpnc10, vrpnc13-vrpnc14) bu sinır bulunmaktadır. $\mathrm{Bu}$ çalışmada, bu problem örneklerinin her biri, rastgele sayl ve permütasyon üretimi için 10 farklı başlangıç çekirdek değeri ile çalıştırılmış ve bu 10 çalıștırmanın ürettiği sonuçların en iyisi, melez GA'nın o problem için bulduğu en iyi sonuç olarak kaydedilmiștir.

Bu çalışmada kullanılan melez GA, aynı problem örnekleri için, sırasıyla bir, iki ve üç bölmeli araç senaryoları için ayrı ayrı çalıștırılmıştır. Her bir örnek üzerinde bir bölmeli ARP için elde edilen toplam tur uzunluğu sonuçları, literatürdeki optimum toplam tur uzunluğu değerleri ile karşılaștırılmıştır (Tablo 1). Yazarın bildiği kadarıyla, iki ve üç bölmeli ARP için mevcut problem örneklerinin literatürde optimum toplam tur uzunluğu değerleri bulunmamaktadır. Bazı çalışmalarda müşterilerin talepleri eşit bir şekilde gerçek sayı olarak bölünmüș ve bu düzenleme için sonuçlar üretilmiștir. Bazı çalışmalarda ise bu bölünmeler rastgele yapılmış ancak çalışmada açık bir şekilde paylaşılmamıştır. Bu çalışmada ise müşterilerin talepleri ve araçların depoları tam sayı olarak (13) ve (14) formüllerine göre belirlenmiștir.

$$
\begin{gathered}
Q_{i}=\left\{\begin{array}{l}
\lfloor Q / m\rfloor, \quad 1 \leq i<m \\
Q-\sum_{i=1}^{m-1} Q_{i}, \quad i=m
\end{array}\right. \\
q_{i j}=\left\{\begin{array}{l}
\left\lfloor D_{i} / m\right\rfloor, \quad 1 \leq i<m \\
D_{i}-\sum_{j=1}^{m-1} q_{i j}, \quad i=m
\end{array}\right.
\end{gathered}
$$

Burada $m$ araçtaki bölme (ya da ürün çeşit) sayısı, $Q$ aracın toplam kapasitesi, $Q_{i} i$. bölmenin kapasitesi, $D_{i} i$. müşterinin toplam talebi, $q_{i j} i$. müşterinin $j$. ürün çeşitine dair talep miktarıdır. Örneğin, $m=3$ için eğer aracın toplam kapasitesi 100 ise, (13) numaralı formüle göre her bir bölmesi sırasıyla 33, 33 ve 34 olmaktadır. Yine $m$ $=3$ için, eğer $i$. müșterinin toplam talebi 11 ise, (14) numaralı formüle göre her bir ürün çeşidi için bu müşterinin talebi sırasıyla 3,3 ve 5 
DEÜ FMD 23(67), 71-80, 2021

olmaktadır. Bu tür bir düzenleme, yazarın bildiği kadarıla, literatürdeki çalışmalarda uygulanmamıştır. Bu tür bir araç ve talep bölünmeleri literatürdeki çalışmalarda kullanılmadığı için, bu çalışmada elde edilen sonuçlar literatürdeki çalışmalardaki sonuçlarla kıyaslanamamıştır. Bu çalışmada $m=1$ için sonuçlar Tablo 1'de $m=2$ ve 3 için elde edilen sonuçlar ise Tablo 2'de verilmiştir.

Tablo 1. Bir bölmeli $(m=1)$ ARP için melez GA sonuçları.

\begin{tabular}{lrrrrr}
\hline Problem & $\mathbf{n}$ & Opt. & melez GA & $\begin{array}{r}\text { Süre } \\
\text { (sn.) }\end{array}$ & Fark \\
\hline vrpnc01 & 50 & 524.61 & $\mathbf{5 2 4 . 6 1}$ & 86.43 & $\% 0.00$ \\
vrpnc02 & 75 & 835.26 & $\mathbf{8 3 5 . 7 7}$ & 39.51 & $\% 0.06$ \\
vrpnc03 & 100 & 826.14 & 828.67 & 150.57 & $\% 0.31$ \\
vrpnc04 & 150 & 1028.42 & 1034.34 & 732.52 & $\% 0.58$ \\
vrpnc05 & 199 & 1291.29 & 1314.48 & 1623.89 & $\% 1.80$ \\
vrpnc06 & 50 & 555.43 & $\mathbf{5 5 5 . 4 3}$ & 44.98 & $\% 0.00$ \\
vrpnc07 & 75 & 909.68 & $\mathbf{9 0 9 . 6 8}$ & 231.38 & $\% 0.00$ \\
vrpnc08 & 100 & 865.94 & 866.87 & 110.65 & $\% 0.11$ \\
vrpnc09 & 150 & 1162.55 & 1176.69 & 86.98 & $\% 1.22$ \\
vrpnc10 & 199 & 1395.85 & 1440.15 & 1935.30 & $\% 3.17$ \\
vrpnc11 & 120 & 1042.12 & 1042.42 & 310.33 & $\% 0.03$ \\
vrpnc12 & 100 & 819.56 & $\mathbf{8 1 9 . 5 6}$ & 7.71 & $\% 0.00$ \\
vrpnc13 & 120 & 1541.14 & 1548.71 & 549.58 & $\% 0.49$ \\
vrpnc14 & 100 & 866.37 & $\mathbf{8 6 6 . 3 7}$ & 215.16 & $\% 0.00$ \\
\hline Ortalama & $\mathbf{1 1 3}$ & $\mathbf{9 7 6 . 0 3}$ & $\mathbf{9 8 3 . 1 3}$ & $\mathbf{4 3 7 . 5 0}$ & $\% \mathbf{0 . 5 5}$ \\
\hline & & & & &
\end{tabular}

Tablo 2. İki $(m=2)$ ve üç $(m=3)$ bölmeli ARP için melez GA sonuçları

\begin{tabular}{|c|c|c|c|c|}
\hline \multirow[b]{2}{*}{ Problem } & \multicolumn{2}{|c|}{$m=2$} & \multicolumn{2}{|c|}{$\mathbf{m}=3$} \\
\hline & $\begin{array}{c}\text { melez } \\
\text { GA }\end{array}$ & $\begin{array}{l}\text { Süre } \\
\text { (sn) }\end{array}$ & $\begin{array}{c}\text { Melez } \\
\text { GA }\end{array}$ & $\begin{array}{l}\text { Süre } \\
\text { (sn) }\end{array}$ \\
\hline vrpnc01 & 542.43 & 228.20 & 553.80 & 355.52 \\
\hline vrpnc02 & 856.94 & 95.58 & 866.83 & 492.03 \\
\hline vrpnc03 & 834.93 & 548.36 & 864.54 & 1614.57 \\
\hline vrpnc04 & 1075.27 & 219.90 & 1107.60 & 6408.27 \\
\hline vrpnc05 & 1379.04 & 1117.15 & 1414.86 & 8437.63 \\
\hline vrpnc06 & 555.43 & 9.08 & 557.49 & 136.12 \\
\hline vrpnc07 & 926.10 & 34.75 & 932.02 & 1369.49 \\
\hline vrpnc08 & 870.08 & 1017.65 & 879.29 & 2280.97 \\
\hline
\end{tabular}

\begin{tabular}{rrrrr}
\hline vrpnc09 & 1198.64 & 1115.37 & 1209.31 & 3436.55 \\
vrpnc10 & 1467.51 & 4209.12 & 1472.83 & 12512.70 \\
vrpnc11 & 1083.53 & 1620.32 & 1242.12 & 1112.22 \\
vrpnc12 & 819.56 & 165.91 & 954.98 & 178.20 \\
vrpnc13 & 1547.09 & 2068.90 & 1545.04 & 4186.10 \\
vrpnc14 & 866.53 & 976.21 & 960.95 & 2809.08 \\
\hline Ortalama & $\mathbf{1 0 0 1 . 6 5}$ & $\mathbf{9 5 9 . 0 4}$ & $\mathbf{1 0 4 0 . 1 2}$ & $\mathbf{3 2 3 7 . 8 2}$ \\
\hline
\end{tabular}

\section{Tartışma ve Sonuç}

Bu çalışmada ÇB-ARP çalışılmış ve sırasıyla bir, iki ve üç bölmeli ARP senaryoları ele alınmıştır. İyi bilinen bir sezgi üstü yöntem olan GA, literatürde bulunan sezgisel arama yöntemleriyle ve de yazar tarafından geliştirilen bir sezgisel arama yöntemiyle melezlenip problemin çözümünde kullanılmıștır. Deneysel çalışmalar, ARP çalışmalarında literatürde yaygın kullanılan Christofides [3] problem örnekleri üzerinde gerçekleştirilmiştir.

$\mathrm{Bu}$ çalışmadaki melez GA, kullanılan problem örnekleri üzerinde, öncelikle bir bölmeli ARP olarak çalıştırılmış ve elde edilen toplam tur uzunluğu sonuçları literatürdeki optimum toplam tur uzunluğu sonuçlarıyla kiyaslanmıştır. $\mathrm{Bu}$ sonuçlara göre, melez GA, üzerinde çalıșılan problem örneklerinin beş tanesinde (vrpnc01, vrpnc06, vrpnc07, vrpnc12 ve vrpnc14) optimum toplam tur uzunluğu sonucunu bulmuş, tüm problem örneklerinde ise optimum toplam tur uzunluğu sonucuna ortalama $\% 0.55$ 'lik bir farkla yaklaşmıştır. Bu başarılı sonuçlarından ardından, melez GA aynı problemin iki ve üç bölmeli senaryolarında uygulanmıştır. Bu makalede ayarlandığı şekilde, bu problem örneklerinin iki ve üç bölmeli ARP sonuçları literatürde bulunmadığından, bu çalışmadaki sonuçlar herhangi başka bir sonuç ile karşılaștırılamamıștır.

Bir, iki ve üç bölmeli ARP'ler için bu çalışmada elde edilen sonuçlara bakıldığında, araçlardaki bölme (müşterilerin ürün çeşitlerinin) sayısı arttıkça, amaç fonksiyonunun değerinin ve algoritmaların işlem sürelerinin arttığ gözlemlenmiștir. Bunun nedeni araçtaki bölme (müşterilerin talep ettiği ürün çeșidinin) sayısının artmasının çözüm temsilindeki permütasyonun boyutunu da artırıyor olmasıdır. Ayrıca, araçların toplam kapasiteleri de bölmelerden dolayı küçüldügü için, bazı 
DEÜ FMD 23(67), 71-80, 2021

durumlarda arac sayısı artmakta bazı durumlarda ise aynı müșterinin farklı ürün talepleri kapasite sınırlarından ötürü farklı araçlara denk gelebilmektedir. $\mathrm{Bu}$ da amaç fonksiyonu olan toplam tur uzunluğunu artırmaktadır. Bölme sayınının artması aynı zamanda ana permütasyonun ve araç turlarındaki permütasyonların boyutunu artmasına neden olduğu için, genel ve yerel arama yöntemleri daha fazla sayıda adımda arama yapmaktadır. Bu da algoritmanın çalışma süresini uzatmaktadır.

Bu çalıșmanın ilgili alana yaptığı katkılar birkaç maddede özetlenebilir. İlk olarak, yazarın bildiği kadarıyla, Türkçe alanda ÇB-ARP alanında yapılan ilk deneysel çalışmadır. İkincisi, literatürde mevcut ÇB-ARP çalışmalarından farklı olarak, araç bölmelerinin ve müșterilerin farklı türdeki ürün taleplerinin tamamıla tam sayı olarak hesaplanmasıdır ((13) ve (14) numaralı formüller). Üçüncüsü, melez GA'da kullanılan yerel arama yöntemlerin birisinin yazar tarafından geliştirilmiş olmasıdır. Dördüncüsü, CB-ARP'nin bu çalıșmadaki ele alınan şekli için elde edilen sonuçlar, bir, iki ve üç bölmeli ARP için bir referans seti oluşturmaktadır.

$\mathrm{Bu}$ makaledeki çalışma, farklı algoritmaların dahil edilip kıyaslanmasıyla, ya da başka amaç fonksiyonlarına (örneğin toplam yakıtın azaltılmasına) göre çözümler yapılmasıyla ve yahut zaman penceresi kisitlamalarının eklenmesi ile geliștirilebilir ve ileriki çalıșmalar olarak ele alınabilir. Ya da gerçek hayattan elde edilen veriler kullanılarak özel örnekler üzerinde çalıştırılabilir.

\section{Kaynakça}

[1] Christofides, N., Mingozzi, A., and Toth, P., "The Vehicle Routing Problem," Rev. française d'automatique, informatique, Rech opérationnelle. Rech. opérationnelle, vol. 10 1979, doi: 10.1051/ro/197610V100551.

[2] El Fallahi, A., Prins, C., and Wolfler Calvo, R., "A memetic algorithm and a tabu search for the multi-compartment vehicle routing problem," Comput. Oper. Res., vol. 35, no. 5, pp. 1725-1741, 2008, doi: 10.1016/j.cor.2006.10.006.

[3] Christofides, N. and Eilon, S., "An Algorithm for the Vehicle-Dispatching Problem," OR, vol. 20, no. 3, p. 309, 1969, doi: 10.2307/3008733.

[4] Mendoza, J. E., Castanier, B., Guéret, C., Medaglia,
A. L., and Velasco, N., "A memetic algorithm for the multi-compartment vehicle routing problem with stochastic demands," Comput. Oper. Res., vol. 37, no. 11, pp. 1886-1898, 2010, doi: 10.1016/j.cor.2009.06.015.

[5] Reed, M., Yiannakou, A., and Evering, R., "An ant colony algorithm for the multi-compartment vehicle routing problem," Appl. Soft Comput. J., vol. 15, pp. 169-176, 2014, doi: 10.1016/j.asoc.2013.10.017.

[6] Goodson, J. C., "A priori policy evaluation and cyclic-order-based simulated annealing for the multi-compartment vehicle routing problem with stochastic demands," Eur. J. Oper. Res., vol. 241, no. 2, pp. 361-369, 2015, doi: 10.1016/j.ejor.2014.09.031.

[7] Abdulkader, M. M. S., Gajpal, Y., and Elmekkawy, T. Y., "Hybridized ant colony algorithm for the Multi Compartment Vehicle Routing Problem," Appl. Soft Comput. J., vol. 37, pp. 196-203, 2015, doi: 10.1016/j.asoc.2015.08.020.

[8] Henke, T., Speranza, M. G., and Wäscher, G., "The multi-compartment vehicle routing problem with flexible compartment sizes," Eur. J. Oper. Res., vol. 246, no. 3, pp. 730-743, 2015, doi: 10.1016/j.ejor.2015.05.020.

[9] Hübner, A. and Ostermeier, M., "A multicompartment vehicle routing problem with loading and unloading costs," Transp. Sci., vol. 53, no. 1, pp. 282-300, 2019, doi: $10.1287 /$ trsc.2017.0775.

[10] Chen, L., Liu, Y., and Langevin, A., "A multicompartment vehicle routing problem in coldchain distribution," Comput. Oper. Res., vol. 111, pp. 58-66, 2019, doi: 10.1016/j.cor.2019.06.001.

[11] Chen, J. and Shi, J., "A multi-compartment vehicle routing problem with time windows for urban distribution - A comparison study on particle swarm optimization algorithms," Comput. Ind. Eng., 2019, doi: 10.1016/j.cie.2019.05.008.

[12] Solomon, M. M., "Algorithms for the Vehicle Routing And Scheduling Problems with Time Window Constraints," Oper. Res., vol. 35, no. 2, pp. 254-265, 1987, doi: 10.1287/opre.35.2.254.

[13] Kaabachi, I., Yahyaoui, H., Krichen, S., and Dekdouk, A., "Measuring and evaluating hybrid metaheuristics for solving the multicompartment vehicle routing problem," Meas. J. Int. Meas. Confed., 2019, doi: 10.1016/j.measurement.2019.04.019.

[14] Wang, L., Kinable, J., and van Woensel, T., "The fuel replenishment problem: A split-delivery multi-compartment vehicle routing problem with multiple trips," Comput. Oper. Res., vol. 118, 2020, doi: 10.1016/j.cor.2020.104904. 
DEÜ FMD 23(67), 71-80, 2021

[15] Eshtehadi, R., Demir, E., and Huang, Y., "Solving the vehicle routing problem with multicompartment vehicles for city logistics," Comput. Oper. Res., vol. 115, 2020, doi: 10.1016/j.cor.2019.104859.

[16] Clarke, G. and Wright, J. W., "Scheduling of Vehicles from a Central Depot to a Number of Delivery Points," Oper. Res., vol. 12, no. 4, pp. 568-581, 1964, doi: 10.1287/opre.12.4.568.

[17] Prins, C., Labadi, N., and Reghioui, M., "Tour splitting algorithms for vehicle routing problems," Int. J. Prod. Res., vol. 47, no. 2, pp. 507-535, 2009, doi: $10.1080 / 00207540802426599$.
[18] Gillett, B. E. and Miller, L. R., "A Heuristic Algorithm for the Vehicle-Dispatch Problem," Oper. Res., 1974, doi: 10.1287/opre.22.2.340.

[19] Croes, G. A., "A Method for Solving TravelingSalesman Problems," Oper. Res., vol. 6, no. 6, pp. 791-812, 1958, doi: 10.1287/opre.6.6.791.

[20] Goldberg, D. E. and Lingle, R. J., "Alleles, Loci and the Traveling Salesman Problem," in Proceedings of the 1st International Conference on Genetic Algorithms, 1985, pp. 154-159, [Online]. Available:

http://dl.acm.org/citation.cfm?id=645511.657 095 . 